faith that medical treatment is a benefit.

The rub, though, is at the margins, in which the desire for solutions for diseases for which there are no easy solutions intersects with padding the profit margins.

These particularly, Cassels advises - much as readers of this book would be best advised - should be taken in small doses, if only to avoid the inevitable urge to seek a pharmacological (or alcoholical) solution to the ensuing depression or paralysis.

\section{Wayne Kondro MA}

News editor

CMAJ

\section{Hospital design:}

\section{form and function}



Medicine by Design: The Architect and the Modern Hospital, 1893-1943 Annmarie Adams University of Minnesota Press; 2008 169 pp \$27.50 ISBN 978-0-8166-5114-6 edicine by Design: The Architect and the Modern Hospital, 1893-1943 advances the idea that hospital design has informed the development of medical care in the 20th century. The author, architectural historian Annmarie
Adams, argues "not that interwar architecture was therapeutically efficacious but rather that it anticipated and produced medical practices broadly and socially conceived, rather than just reflected them symbolically."

It has been more common to assume that the organization and interiors of hospitals are functions of treatment and technology, while exteriors expressed tastes prevailing for public institutions.

Adams' book is intended to open up the topic rather than provide a comprehensive history.

It focuses on the period 1893-1943 in Canada, and specifically 2 case studies: one of the Royal Victoria Hospital in Montréal, Quebec, and the other of the practice of architects Edward Stevens and Frederick Lee, specialists in the design of hospitals. Chapters about patients and nurses complete a detailed picture of the day-to-day life in hospitals up to the Second World War.

Their physical forms, often resembling the great railway hotels with their references to castles and baronial houses reflected a concern that remains with us today - the provision of care during often frightening, even lifethreatening circumstances, in a setting that is both comforting and suited to technology and efficiency.

It is interesting to note that early hospitals were for the poor. Those who could afford it paid for care at home. When modern purpose-built hospitals were established they needed to attract paying patients: the middle classes and the wealthy. To that end, they borrowed details from the design of luxury hotels and aristocratic houses such as pitched roofs, classical entries and interior molding.

Yet, their traditional facades concealed the latest technology of the early 20th century.

Behind the double-height Corinthian columns of Montréal's Hopital-Notre Dame, was a department for otolaryngology. The Hospital for Sick Children in Toronto, Ontario boasted a room for pasteurizing milk. And the inclusion of lounges in the maternity pavilion at the Royal Victoria Hospital "shows how architecture served as a tool in the modern concept of recuperation from birth."

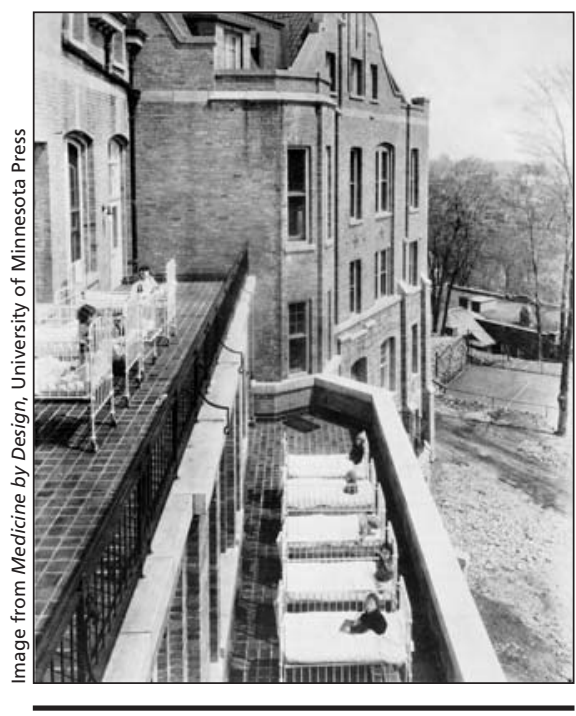

Young patients at the Children's Memorial Hospital occupied rooftops (Figure 2.25 in the book).

While conservative in style, hospital buildings pioneered many modern ideas. They were among the first buildings to be mechanically ventilated and to be designed for cars; as early as 1911 the Royal Victoria had parking lots for doctors and private patients. With nurses residences and on-site education, they created opportunities for women outside the home, a dramatic social transformation made easier by the domestic character of hospital spaces.

The book is scholarly but leavened by fascinating early photos (among them an image of the surgical theatre at the Royal Victoria in 1894 with its dramatic semicircular tiered seating) and colourful tidbits. For instance, we are told Florence Nightingale, the pioneer of modern nursing, criticized the design for the Royal Victoria Hospital. "Duty room is as far from the ward as it can be," she wrote in 1899. "In fact it should called off-duty room."

This book is informative reading for anyone interested in form and function in the evolution of modern hospital architecture.

\section{Maria Cook \\ Journalist}

Ottawa, Ont.

Maria Cook is a staff writer at the Ottawa Citizen specializing in architecture and urbanism. 